ORIGINAL ARTICLE

\title{
Principlism or narrative ethics: must we choose between them?
}

\section{J McCarthy}

J Med Ethics; Medical Humanities 2003;29:65-71

This paper addresses a current debate in the bioethics community between principlists, who consider that principles are at the heart of moral life, and narrativists, who see communication at its core. Using a case study entitled "The forgetful mourner" to introduce the tensions between each of these positions, I go on to explain the central tenets of both principlism and narrative ethics. Rather than focus on their respective weaknesses, which many theorists do, I emphasise instead, the contribution that each approach can make to understanding moral life and the process of ethical decision making in health care situations. My ultimate aim is to identify the, sometimes overlapping, skills that both principlism and narrative ethics require on the part of health professionals who deploy them. I conclude that a good principlist has narrativist tendencies and a good narrativist is inclined toward principlism.

Correspondence to: Joan McCarthy, PhD, Department of Nursing Studies, University College Cork, Ireland:

j.mccarthy@ucc.ie

Accepted 4 June 2003
$\mathrm{T}$ his paper examines and tests the parameters of a debate that has been taking place in the bioethics community in recent years. The debate is best expressed as one between those theorists who see principles at the heart of moral life and those who see communication at its core. The former position is generally described as principlism; the latter, has become known as narrative ethics. I intend to explain and assess these positions, not, however, with a view to privileging one over the other: many books and articles have already been written which point to serious weaknesses in both of them. (For some of the standard criticisms of principlism see: Clouser KD and Gert B, ${ }^{1}$ DuBose ER, Hamel RP and $\mathrm{O}^{\prime}$ Connell $\mathrm{LJ},{ }^{2}$ and Davis RB. ${ }^{3}$ For some of the standard criticisms of narrative ethics, see: Clouser KD, ${ }^{4}$ and Lindemann Nelson H. ${ }^{5}$ ) Rather, I want to present each perspective in its best light, highlighting its positive features and strengths. Ultimately, my intention is to identify the skills that each of these approaches require on the part of health professionals who deploy them.

To begin my exploration of principlism and narrative ethics, I examine a case study and, in turn, a moral issue that regularly arises when caring for people with Alzheimer's disease. This case, published in the Hastings Center Report (1995), and entitled "The forgetful mourner" concerns an eighty six year old Italian American woman with moderate dementia, Mrs C. ${ }^{6}$ She is admitted to a nursing home when her son Tony, with whom she has been living, falls ill. When, after two years, Tony dies suddenly the staff in the nursing home are especially concerned for Mrs C. In the days and weeks that follow the funeral, she continues to ask how Tony is doing as if he is still alive.

After consulting with staff, the director of the Alzheimer unit, Dr L, decides that Mrs C's questions should be answered truthfully: she should be told that Tony has died. Each time this is done, however, Mrs C becomes distraught, enduring the pain of her son's death over and over again. While everyone finds this very hard, Dr L hopes that their patience and persistence will enable Mrs C to remember what really happened. The only alternative seems to be a grave and sustained deception on the part of everyone who has a relationship with Mrs C.

As it turns out, Mrs C is told of her son's death at least fifteen times, and each time she experiences the grief of her loss anew. Then, one of the nurses, Ms F, suggests that Mrs C put on the black dress she had been wearing on the day she attended Tony's funeral. This she does and it seems to help her to remember. Even though Mrs C continues to talk about Tony, she no longer asks how he is doing.

The two commentaries that follow the case of "The forgetful mourner" take opposite views of the response of Dr L to Mrs C's bereavement. ("The forgetful mourner" is also discussed in the light of the different responses of Dr L and Ms F in Parker $M$ and Dickenson $D .^{7}$ ) The first commentary, by Tony Yang-Lewis, is sympathetic toward both Dr L and Ms F. He takes the view that, however painful it is, in this case, communicating the truth to Mrs C, in whatever fashion, is the right and respectful thing to do because it acknowledges the importance of her relationship with her son. According to YangLewis, it is Mrs C's memory that is eroded, but not necessarily her sense of self-and her relationship with her son is integral to that sense of self. ${ }^{8}$

The second commentary, by Harry R Moody, however, takes a much harsher line and remarks: "No more poignant example of fanaticism is imaginable than the devotion to abstract principle-truth telling-revealed by this case ${ }^{\prime \prime}$. ? Arguing that Dr L's devotion to truth telling is misguided because it ignores the anguish and pointless pain of the patient that it causes, Moody heaps praise on the experimental and imaginative approach of Ms F, which he sees as 
an alternative to the "philosophical faith" or "creed" of principlism. He takes the view that Ms F's action in relation to the black dress is motivated not by the principle of truth telling, but by the desire to communicate with the patient in a way that does not prejudge the outcome. The immediate effect of the black dress, for Moody, is that it validates Mrs C's sense of loss. Ultimately, it may or may not succeed in getting Mrs C to understand and accept the truth about her son. In sum, it is communication, not principlism, which is key to moral life for Moody. Note that while Moody is hostile to what he calls, "principlism", he is not completely adverse to principles because at the end of his commentary, he suggests that we should forge a "communicative ethic" which unites principles and prudence with experiment and practical imagination. ${ }^{9}$ This paper hopes to contribute in some way to the development of such a position.

\section{PRINCIPLISM}

What is known as the principlist approach to ethical decision making has dominated Western bioethics for the last twenty years. It emerged with the publication of several well known texts in the 1970s and 80s. One of these was the Belmont Report which identified basic principles that would underlie and guide the regulation of research involving human subjects. ${ }^{10}$ Three books, also published at that time, outlined and defended a principlist ethical framework, those of Tom Beauchamp and James Childress, Robert Veatch, and $\mathrm{H}$ Tristram Engelhardt. ${ }^{11} 1213$

This paper examines the account developed by Beauchamp and Childress in their book, Principles of Biomedical Ethics. What is especially attractive about this particular principlist model (hereafter called the PBE model) is that, since its first appearance in 1979, the authors have continuously refined and honed its central elements in response to numerous objections that have been made to it over the years. This reworking of their position has, I think, made it more resistant to the problems endemic to principlism generally and more inclusive of other features of the moral world that it had, initially, ignored.

The PBE model is an ethical decision making process which negotiates between fundamental principles, on the one hand, and the unique nature of specific moral situations on the other. It makes three central claims which I will, first, briefly summarise and then examine in more detail.

1. Basic principles and the specific action guiding rules that are derived from them are central to the ethical decision making process in health care situations.

2. In any given health care situation, any decision or course of action is morally justified if it is consistent with relevant principles, rules, background theoretical commitments, and particular judgments.

3. The success of the task of justification in 2 can be measured by the degree to which it achieves an overall cohesion of all of the elements of the decision making process.

1. On the PBE model, while background theories such as those concerning human nature or personhood and the particular judgments we make in concrete situations are considered to be important elements of the ethical decision making process, four basic principles are privileged:

- autonomy: respect the views, choices, and actions of others

- non-maleficence: avoid causing harm

- beneficence: act for the benefit of others

- justice: treat people fairly
A good deal of the Principles of Biomedical Ethics text is taken up with an analysis and discussion of each of the four principles in terms of their nature and scope. In particular, the specific rules that are supported by these principles and that permit, prohibit, or require particular kinds of action are delineated. These include rules governing truth telling, privacy, confidentiality, and informed consent. ${ }^{14}$

What is special about these principles is their supposed universal or objective nature. Beyond tradition, individual vagaries, and culture, Beauchamp and Childress claim that these principles have been drawn from a "common morality", the set of norms that "all morally serious persons share" (Beauchamp T, Childress J, ${ }^{14}$ p 3). According to them: "The common morality contains moral norms that bind all persons in all places; no norms are more basic in the moral

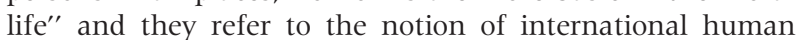
rights as an example of such universal norms (Beauchamp T, Childress $J_{1}{ }^{14} \mathrm{p} \mathrm{3}$ ). Having grounded their four principles, they justify their particular choice by pointing out that these four have been presupposed by traditional ethical theories and medical codes throughout history.

2. The most immediate way to decide on the merits of a proposed course of action, on the PBE model, is to determine whether or not that course of action obeys the moral rules that are derived from the four principles, On this view-for example, a health professional might consider that it is, generally, morally required to provide a patient with information about their illness because this action obeys the moral rule "Tell the truth" which is, in turn, derived from the principle, "Respect patient autonomy".

In morally difficult situations, however, where there is a conflict between principles, or between principles and particular judgments, the PBE model stipulates that none of the principles is a priori privileged. In any given situation, each principle must be specified and weighed relative to the particular context in which it is applied and informed by generally accepted background theories of human life and nature. Following John Rawls, this weighing and balancing is described as a process of "reflective equilibrium" and the principles are described as prima facie rather than absolute (Beauchamp J, Childress T, ${ }^{14}$ p 398). This is to express the idea that any one principle is, on first impression, morally obligatory but that it may be modified or overridden in certain situations. In the case of "The forgetful mourner"for example, Ms F might initially believe, along with Dr L, that telling Mrs $\mathrm{C}$ the truth about her son's death is the morally correct thing to do. In the actual face to face encounter with Mrs C, however, she seems to balk at the pain she inflicts and desists. In this case, it could be argued that it is her particular judgment in the concrete situation which prompts her to reconsider whether the rule of truth telling, or some other rule, should apply here.

3. As 2 indicates, the process of reflective equilibrium involves the specification, reciprocal weighing, testing, revising, and balancing of principles, rules, background theories, and particular judgments. For Beauchamp and Childress, the objective here is to reduce any conflict among our beliefs by fitting them into a coherent whole:

So called wide reflective equilibrium occurs when we evaluate the strengths and weaknesses of all plausible moral judgments, principles, and relevant background theories. Here we incorporate as wide a variety of kinds and levels of legitimate beliefs as possible, including hard test cases in experience. ... No matter how wide the pool of beliefs, we have no reason to anticipate that the process of pruning, adjusting, and rendering coherent will either come to an end or be perfected. A moral framework is 
more a process than a finished product; and moral problems ... should be considered projects in need of continual adjustment by reflective equilibrium (Beauchamp J, Childress J, ${ }^{14}$ p 399).

On this understanding, the processes of moral deliberation are akin to scientific processes: they involve the setting up of hypotheses that are tested and modified or rejected on the basis of reasoning and experience. In turn, the aim of unifying all one's moral beliefs and background commitments is analogous to the scientific goal of achieving theoretical consistency and unity.

What is clear from this account of the PBE model is that, granted each of its three key claims, it provides a method of supporting ethical decisions that has a strong justificatory force. Put simply, on this view, the force of the imperative, "Tell the truth", derives from its grounding in universally accepted norms, not-for example, in the subjective viewpoint or intuition of the health professional. Moreover, even in situations of doubt and uncertainty, such as that of "The forgetful mourner", the deliberative process which comes into play appeals to reasoning strategies and goals that are also considered objective, not intuitive.

\section{NARRATIVE ETHICS}

While different shades of principlism have dominated the health care landscape in the last twenty years, an increasing number of theorists have begun to turn their attention to alternative approaches to describing and understanding the various elements of moral life. One such approach deploys narrative concepts and methodologies drawn from literary criticism and philosophy as tools of moral understanding and assessment. For critical examinations of different narrative approaches to bioethics see Lindemann Nelson H. ${ }^{15}{ }^{16}$ See also Greenhalgh and Hurwitz, who insist on the need for clinical training in interpretative skills to improve the diagnosis and treatment of illness. ${ }^{17}$ See also Montgomery Hunter K for a short overview of the role of narrative theory in bioethics. ${ }^{18}$ In common with contemporary thinkers in other disciplinesfor example, anthropology, philosophy, cognitive psychology, and history, who have turned their attention to narratives, narrativists in the health care arena argue that the first person narrative, or personal story, is a rich medium for qualitative data about the unique lives of individual people. Further, for some of these theorists, the narrative is not only an important form of communication, it is also a means of making human life and, specifically the moral life, intelligible. (The meaning of the term "narrative" invokes two kinds of activities-telling and knowing. "Narrative" comes via the Latin terms: narrö [relate, tell] from the original Sanskrit root gnâ [know] and gnärus [knowing, acquainted with, expert, skilful]). ${ }^{19}$ While they deploy narrative tools in different ways, I suggest that all of these thinkers are engaged in "narrative ethics". For a dissenting view see Hudson Jones A. ${ }^{20}$

Martha Nussbaum-for example, views literature as a vast resource of moral knowledge and a means of sensitising people to the responsibilities, obligations, and challenges of a full moral life..$^{21}{ }^{22}$ Alternatively, the narrative approaches of Albert Jonsen, Stephen Toulmin, and John Arras take a casuistic turn and resolve ethical dilemmas by comparing each new situation with others and with paradigm cases. ${ }^{23}{ }^{24}$ These authors argue that local, contingent moral rules and maxims to guide action can be derived from paying attention to the morally relevant similarities and differences between cases.

More recently, Rita Charon has suggested that our understanding of medical cases will be greatly enhanced if we pay attention to their narrative elements-for example, the function of the narrator or author, the development of plot, and the relationship between text and reader(s). ${ }^{25}$ In addition to supporting Charon's view, Tod Chambers has sparked a lively debate in the bioethics community, arguing that the task of reporting cases is itself, not a neutral enterprise. ${ }^{26}$ This is because, he argues, the process of describing any set of events involves decisions about including or excluding certain pieces of information and making choices about the way different facts are presented.

Finally, narrativists such as Howard Brody, Arthur Frank, Kathryn Montgomery Hunter, Alasdair MacIntyre, Paul Ricoeur, and Margaret Urban Walker argue, not only that the narrative approach to morally difficult situations enhances existing models of decision making such as principlism, but that the narrative approach is itself theoretically robust. ${ }^{27-34}$ At the very least, it radically challenges the theoretical adequacy of models such as principlism. At best, it provides an alternative means of justifying ethical decisions which focuses on the relational and communicative dimensions of moral situations.

Because narrative ethics is in its early stages of development, there is, as yet, no ready to hand canonical position that best expresses its central tenets. Indeed, as I have indicated, "narrative ethics" is a term which covers a very diverse range of thinkers, from those who view narratives as a rich resource for existing ethical theories, to those who see the concepts and methodologies associated with the study of narratives as the foundation of a bioethical theory that can serve as an alternative to traditional models. In what follows, I will roughly sketch what I see as the most plausible and defensible account of narrative ethics. It is also one which highlights the tensions between narrative ethics and principlism and exposes the congruities and incongruities between these supposedly competing positions. The central tenets are:

1. Every moral situation is unique and unrepeatable and its meaning cannot be fully captured by appealing to law like universal principles.

2. In any given health care situation, any decision or course of action is justified in terms of its fit with the individual life story or stories of the patient. These, in turn, are understood and assessed on the basis of "narrative reflective equilibrium".

3. The objective of the task of justification in 2 is not necessarily to unify moral beliefs and commitments, but is to open up dialogue, challenge received views and norms, and explore tensions between individual and shared meanings.

1. For narrativists, understanding an individual's life as a narrative and deploying narrative methodologies to read and interpret it, broadens and enriches our understanding of that life and deepens our insight into the relationship between the unravelling of human life and moral agency.

On this view, when ethically challenging situations arise, it is not the medical chart, the proposed treatment, and the ethical rules that might govern that treatment which are at the centre of moral interest. Rather, it is the whole journey of an individual's life as they conceive it themselves that is privileged. Howard Brody-for example, sees the practice of medicine, in part, "as a storytelling enterprise":

The concept of "story" suggests appreciation of a narrative mode-that certain sorts of events can be fully understood only as portions of certain ongoing narrative and not as disconnected events occurring in isolation. In contrast, much of modern medical ethics is "rule" and "decision" oriented, suggesting that precisely such an 
ahistorical, non-narrative form of ethical analysis is optimal (Brody $\mathrm{H}_{,}^{27} \mathrm{p}$ xiii).

For Brody, actions are made meaningful in the context of an individual life story. As such, it is difficult to isolate any given decision or choice, to uncouple it from the whole person who acts, and to evaluate it in terms of abstract and general rules.

2. Narrativists approach the question of moral justification in a variety of different ways. Alasdair MacIntyre, for example, claims that what is significant about human beings is not their ability to make choices (and so obey or disobey universal rules) but their social embeddedness. ${ }^{30}$ He considers that an individual's very capacity for choice is shaped, enabled, and made meaningful by the traditions of her or his community. In turn, he argues that the moral acceptability of any given choice can be measured in terms of its consistency with the narrative unity of an individual life-past, present, and future-and in terms of its coherence with whatever deep values and conceptions of the morally good life are already established in the communities in which the individual lives (MacIntyre A, ${ }^{30} \mathrm{pp}$ 181-225).

Others argue that the narrative approach cannot justify privileging one choice over another in moral situations. Postmodernists such as Michel Foucault, for example, claim that the whole narrativist project is ill fated from both a moral and an epistemic point of view. ${ }^{35} \mathrm{He}$ argues, firstly, that the cycle of a human life is characterised more by its fragmentation than its unity and, secondly, that narrative interpretation invokes a range of different narrative forms and genres, not a single authoritative reading as MacIntyre would have it. If several stories can be told about a life that is, itself, not internally coherent, then it is neither possible to fit any given action unambiguously within a single life story, nor to evaluate it within the terms of a single tradition.

Following philosophers such as Paul Ricoeur, Margaret Urban Walker, and Hilde Lindemann Nelson, however, I want to defend a third and more moderate view of narrative justification..$^{151-34}$ On this account, the first person narrative is prima facie privileged. Not any tall tale will do, however, and personal stories are tested against various criteria, such as the stories of others and available documentary evidence. Why? Firstly, because as we all well know, we are wont to be naïve, mistaken, and delusional about our beliefs and self understandings. Secondly, as Lindemann Nelson argues, our self conceptions rely on the conceptions of others to make them genuinely identity constituting-for example, I cannot seriously view myself as someone who can teach health care ethics unless some other folk see me that way too. In her innovative and insightful book, Damaged Identities: Narrative Repair, Lindemann Nelson challenges traditional notions of moral agency, understood as rational choice, and instead, understands the capacity for moral decision making as enabled or disabled by the degree to which an individual's life story, and their sense of self, fits or fails to fit with the dominant narratives of that individual's community. ${ }^{16}$ Thirdly, our self conceptions are contextual: they get constructed within culturally available narratives which both enable and limit the kinds of people we can imagine ourselves to be.

On this narrative account, the more credible stories are those that capture what it is about our lives that matters most to us. They are intelligible, consistent with biographical events, and consistent with what we actually do. They also explain best why we take responsibility for our actions, why some things matter to us more than others, why we love or hate, and why we are happy or hurt. Here I am indebted to Lindemann Nelson's account of narrative justification. (Lindemann Nelson $\mathrm{H}^{16}$ pp 92-105). I liken this idea of testing personal narratives against various criteria to the way in which the principlist model tests its principles through the application of the process of reflective equilibrium. In the case of the PBE model, the four principles are prima facie privileged, but may be modified subsequently. On the narrative view, it is first person narratives that are prima facie privileged; however, like principles, they can be challenged and modified in the process of what I am calling, a "narrative reflective equilibrium". The final story or account of a life that emerges from such evaluation is described by Ricoeur, recalling the Socratic ideal, as "the fruit of an examined life" (Ricoeur P, ${ }^{31}$ pp 246-7).

In recent years, a narrative approach of this kind has contributed to discussion and debate in relation to end of life decisions. It informs, for example, one of the recent recommendations of the US Council on Ethical and Judicial Affairs which suggests that, when it comes to making decisions for incompetent patients, one of the tasks of a surrogate decision maker is to consider "how the patient constructed his or her identity or life story" in order to reach a decision about a proposed course of treatment that continues the story "in a manner that is meaningful and consistent with the patient's self conception". ${ }^{36}$ In addition, the council argues that it is precisely the fact that a number of different options might be consistent with a person's life story which makes the narrative approach so attractive because it avoids having to predict only a single course of action as compatible and, therefore, morally acceptable. See also Kuczewski MG for a discussion about the relationship between narrative and substituted judgment. ${ }^{37}$

3. The third tenet of narrative ethics is the claim that the task of moral justification is not, primarily, a unifying one. Rather, its focus is on acknowledging and embracing the multiplicity of, often contested, meanings that are available in any given situation. What is key for this narrativist account is the idea that many different voices and readings of moral situations and individual lives are possible. And, generally, narrativists focus less on trying to reduce competing perspectives to a commonly shared view and more on involving as many people as possible in the dialogue. Anne Hudson Jones summarises this view thus:

In ideal form, narrative ethics recognises the primacy of the patient's story but encourages multiple voices to be heard and multiple stories to be brought forth by all those whose lives will be involved in the resolution of a case. Patient, physician, family, health professional, friend, and social worker-for example, may all share their stories in a dialogical chorus that can offer the best chance of respecting all the persons involved in a case (Hudson Jones $A,{ }^{20} p$ 222).

In turn, for narrativists, relational virtues such as empathetic listening and support are privileged. In the course of such privileging, these virtues are reworked to acknowledge and accommodate the narrative view that, in some senses, difference is irreducible. Howard Brody, for example, radically reconceives the moral demands of "empathy" in the following passage:

In a culture that prizes autonomy and independence, we may fondly imagine that most people are whole and intact, unlike those who suffer from disease. ... Charity tends to assume that I start off whole and remain whole while I offer aid to the suffering. Empathy and testimony require a full awareness of my own vulnerability and radical incompleteness; to be with the suffering as a 


\begin{abstract}
co-human presence will require that I change. ... Today I listen to the testimony of someone's suffering; tomorrow that person (or someone else) will be listening to my testimony of my own. Today I help to heal the sufferer by listening to and validating her story; tomorrow that sufferer will have helped to heal me, as her testimony becomes a model I can use to better make sense of and deal with my own suffering (Brody $\mathrm{H}_{,}{ }^{27}$ pp 21-2).
\end{abstract}

On Brody's view, the demand of empathy does not require us to "step into another's shoes" in order to understand their pain. It does not presuppose that it is ever possible fully to understand another's pain. The other person is always "other" to us, her difference persists, resisting assimilation under the umbrella of mutual understanding. Instead, empathy demands that we bear witness to our own vulnerability and lack so that we stand, not as whole to part, or healthy to ill, but as a "co-human presence". On this view, health professionals cannot offer patients the reassurance that they know and understand them, only the acknowledgement that they have listened and heard. On this view too, no health professional is untouched by a patient's pain and vulnerability, there is professional engagement, not detachment.

What is refreshing about the account of narrative ethics outlined above is that it introduces the idea that the aim of ethics is not, necessarily, to reduce discord, disunity, and disagreement. Where principlism is lauded because of its justificatory force-for example, its supposed objective rules distinguishing between good and bad actions, and its theoretical consistency, by contrast narrative ethics, as we have seen, slides toward relativism and diversity with seemingly wild abandon (MacIntyre excepted). Some might see this slide as good reason to abandon narrative ethics for the more stable and theoretically satisfying principlist position. What if, however, one were to view the relativism of narrative ethics not as a failure of comprehensiveness or probity or insight, but rather, as pointing the way toward a reframing of what we understand the task of ethics to be?

\section{THE STRENGTHS OF PRINCIPLISM AND NARRATIVE ETHICS}

As my brief sketches indicate, the explicit theoretical commitments of principlism and narrative ethics are very different. Principlism takes a systematic approach to ethical decision making and aims to render our deeply and confidently held moral convictions into a consistent and unified approach. On the other hand, narrative ethics takes the individual life story in its unrepeatable uniqueness as the starting point, and resists tendencies to generalise, even at the risk of being accused of theoretical inadequacy. Given the differences in their approaches, both positions have readily identifiable strengths.

Firstly, as Beauchamp and Childress rightly claim, the PBE model of principlism provides a clear method and vocabulary for identifying and articulating ethical concerns in health care situations and for negotiating moral ideas and arguments. Specifically, if offers a simple ethical framework within which to analyse, examine, and address the increasingly complex issues that have emerged in bioethics in the past forty years, such as new reproductive technologies, organ and tissue transplantation, genetic engineering, and the allocation of scarce resources.

Secondly, the PBE model is a particularly useful means of drawing the parameters of moral relationships between strangers. Following in a liberal and pluralist tradition, the authors' adoption of the four principles reflects their concern to devise a method of decision making that adheres to rules that people with different cultural backgrounds and world views would consider morally acceptable. On the PBE model, the four principles are considered to be binding on all moral persons irrespective of culture or creed. This attempt to open up a gap between individual intuition and generally acceptable moral norms means that the PBE account is a particularly important tool for legislators and public policy makers, whose task is to regulate the conduct of various individuals, groups, and institutions with different background views and agendas (such as in the case of research facilities, hospitals, infertility clinics etc). At an individual level, the four principles constrain and enable the conduct of the health professional who must, for example, respect his or her patients' autonomy and right to fair and equal treatment irrespective of religious, moral, or social differences between them.

The strength of narrative ethics, on the other hand, is that it provides a method and vocabulary for interpreting and respecting the unique and personal stories of individuals. On this view, any decision about medical treatment or health care must be considered in the light of the patient's individual story or stories.

In addition, narrative ethics is strongly engaged with the concrete and intersubjective lives of people. Where the focus of principlism is on an "ethics of strangers", narrative ethics places emphasis on the professional/patient relationship as itself an ethical realm which is personal and affective. In this realm, intimacy, vulnerability, and suffering haunt each ordinary encounter and cannot be acknowledged or addressed simply by obedience to rules. Knowing why it is morally appropriate to listen to someone's account of her suffering is not the same as being there and knowing when and how to do the listening. To do that, a person must not only hold moral principles, these values must be integrated into one's life and heart.

Given the respective strengths of principlism and narrative ethics, we might ask ourselves: must we be principlists, wedded to the pursuit of an abstract, universal, comprehensive, detached, impartial, objective, neat, exact, clear, coherent system of ethical decision making? Or, must we be narrativists cherishing the concrete, particular, provisional, personal, partial, subjective, excessive, woolly, fuzzy, engaged, fragmented dimensions of human life? If the task of ethics is to develop and defend systematic approaches to decision making, then the PBE model certainly seems to be such a theory. On the other hand, if the business of ethics is to foster skills of interpretation and communication, the theory of narrative ethics seems a better candidate.

Casting "ethics", along with its aims and objectives, as wholly one kind of pursuit or another seems, however, ultimately foolhardy and counterproductive. Given that the parameters of "ethics" have been drawn and redrawn for centuries-think of Plato, Aristotle, the Stoics, Christianity, Islam, Kant, Bentham-there is no single account of the task of ethics that is not historically and culturally constrained in some way. Given that both principlism and narrative ethics can be viewed as theoretical attempts to articulate a range of ethical concerns that affect many people, a more modest question is called for: what skills should health professionals have in order to be able to deploy these different ethical theories in their practice? Posing such a question makes it possible to move the emphasis away from the philosophical tensions and conflicts between principlism and narrative ethics, and attend instead to the ways in which each of these theories can help the health professional to make good ethical decisions.

\section{PRINCIPLIST AND NARRATIVIST SKILLS}

For principlists and narrativists certain sets of skills are important. To be a "good" principlist one must have: (1) 
conceptual and analytic skills to identify moral issues and specify principles; (2) deductivist skills such as the ability to apply general principles to particular cases; (3) critical skills to assess and weigh principles and arguments, and (4) reflective skills such as the ability to reflect on and reason from particular experiences and cases to general rules.

Alternatively, to be a "good" narrativist one must have: (1) literary skills and vocabulary to understand and interpret the patient's story; (2) critical skills such as the ability to fit actions within a larger frame of meaning; (3) reflective skills such as the ability to consider and test multiple narratives, and (4) communicative skills, in order to negotiate the professional/patient realm, such as the ability to "empathise" (in Brody's sense) with the patient's story. Narrativists discuss narrative skills in different ways. See-for example, Montgomery Hunter K, Charon R, and Coulehan JL's paper in Academic Medicine ${ }^{38}$ where they list a number of narrative competencies that would better equip health care professionals for ethical decision making. These include a range of abilities: to closely observe and identify patterns of meaning; to follow complex plots; to imagine and be empathetic to other life stories and experiences; to understand different cultural, social, and religious perspectives, and to grow in self awareness and self criticism. Or, see Hudson Jones's paper in HEC Forum, which emphasises three sets of narrative skills that can be summarised as (1) interpretive (reading and interpreting), (2) communicative (telling and writing), and (3) interpersonal and empathetic. ${ }^{39}$

In sum, principlism primarily requires those skills which force us to take a reflective step back from our intuitive response to a situation and to determine instead what general norms might apply in that instance. On the other hand, while narrative ethics also challenges health professionals to step outside of their received values, its emphasis is on individual people, their unique stories and circumstances and so, for narrativists, communicative skills are central. These sets of skills are not, however, mutually exclusive. Both principlists and narrativists-for example, require critical and reflective skills. Moreover, while principlists privilege the move from general rules to particular cases they nevertheless take individual situations, and the particular judgments these call for, very seriously in their overall aim of unifying all of the elements of the moral process. In the same way, while narrativists privilege the personal story and unique situation, they nevertheless interpret these within a more general framework of multiple stories and shared understandings.

\section{CONCLUSION}

However different and conflicting principlist and narrative theories appear to be, they point to important ethical skills that health professionals should have, and, as I have argued, these skills often overlap and reinforce one another. This is evident in the case of "The forgetful mourner" and the two commentaries of Moody and Yang-Lewis.

Given the account of narrative ethics that I have articulated in this paper, which privileges life stories as a source of personal and moral intelligibility, it could be argued that Dr L's decision to tell and retell Mrs $C$ the truth about her son is not, simply or solely, a case of principlism run riot. While Moody's hostile response to Dr L's decision would have us believe that this is so, Yang-Lewis argues that the decision of the doctor and the nurse to communicate the truth to Mrs C is morally justified because it supports her sense of self: the act of telling her the truth fits with the story of Mrs C's life in which her son, Tony, plays a very important part. On this view, Dr L's and Ms F's actions are warranted, not necessarily because they are guided by principles, but because they are informed by what these health professionals know of Mrs C's life story.
In short, the decision to tell Mrs $\mathrm{C}$ the truth can be morally justified within the terms of both principlism and narrative ethics. It follows that the justifiable concern which Moody and many others might have with the doctor's persistence with "truth telling" does not, necessarily, lead to the conclusion that the fault lies with principlism. The challenge for the health professionals in this case lies not in the choice of ethical theory-either one will do-but in their application of it. What Dr L lacks and Ms F has in spades is moral imagination and moral imagination is as much a requirement of good principlism as it is of good narrative ethics. It would seem that a "good" principlist pays attention to the uniqueness of each moral situation and so, has narrativist tendencies, and a "good" narrativist has a view to multiple stories and shared meanings and, so, is inclined toward principlism.

\section{REFERENCES}

1 Clouser KD, Gert B. A critique of principlism. J Med Philos 1990;15:219-36.

2 DuBose ER, Hamel RP, O'Connell U. A matter of principles? Ferment in US bioethics. Valley Forge, PA: Trinity Press International, 1994.

3 Davis RB. The principlism debate: a critical overview. J Med Philos 1995; 17:511-39.

4 Clouser KD. Philosophy, literature, and ethics: let the engagement begin. JMed Philos 1996;21:321-40.

5 Lindemann Nelson H, ed. Stories and their limits. New York: Routledge, 1997.

6 Anon. The forgetful mourner [editorial]. Hastings Cent Rep 1995;25:32.

7 Parker M, Dickenson D. The Cambridge medical ethics workbook. Cambridge: Cambridge University Press, 2001:125-59.

8 Yang-Lewis T. Commentary. Hastings Cent Rep 1995;25:32-3.

9 Moody HR. Commentary. Hastings Cent Rep 1995:25:33.

10 National Commission for the Protection of Human Subjects of Biomedical and Behavioral Research. Belmont report. Washington DC: Government Printing Office, 1979; www. http://ohsr.od.nih.gov/mpa/belmont.php3 (accessed 3 Mar 2003).

11 Beauchamp T, Childress J. Principles of biomedical ethics. New York: Oxford University Press, 1979.

12 Veatch R. A theory of medical ethics. New York: Basic Books, 1981

13 Engelhardt HT. The foundations of bioethics. New York: Oxford University Press, 1986.

14 Beauchamp T, Childress J. Principles of biomedical ethics [5th ed]. Oxford: Oxford University Press, 2001:57-112.

15 Lindemann Nelson H, ed. Stories and their limits. New York: Routledge, 1997.

16 Lindemann Nelson H. Damaged identities, narrative repair. New York: Cornell University Press, 2001:36-68.

17 Greenhalgh T, Hurwitz B, eds. Narrative based medicine. London: BMJ Books, 1998

18 Montgomery Hunter K. Narrative. In: Warren TR, ed. Encyclopedia of bioethics. New York: Simon \& Schuster Macmillan, 1995: 1789-94.

19 White H. The content of the form: narrative discourse and historical representation. Baltimore and London: The Johns Hopkins University Press, 1987:1, 215.

20 Hudson Jones A. Narrative in medical ethics. In: Greenhalgh T, Hurwitz B, eds. Narrative based medicine. London: BMJ Books, 1998:217-24.

21 Nussbaum MC. Love's knowledge. New York: Oxford University Press, 1992

22 Nussbaum MC. Poetic justice: the literary imagination and public life. Boston: Beacon Press, 1995.

23 Jonsen A, Toulmin S. The abuse of casuistry: a history of moral reasoning Berkeley: University of California Press, 1988.

24 Arras J. Getting down to cases: the revival of casuistry in bioethics. J Med Philos 1991;16:29-51.

25 Charon R. Narrative contributions to medical ethics: recognition, formulation, interpretation, and validation in the practice of the ethicist. In: DuBose ER, Hamel RP, O'Connell $\amalg$, eds. A matter of principles? Valley Forge, PA: Trinity Press International, 1994:260-83.

26 Chambers T. The fiction of bioethics: cases as literary texts. New York: Routledge, 1999.

27 Brody H. Stories of sickness. New Haven and London: Yale University Press, 1987.

28 Frank A. The wounded storyteller: body, illness and ethics. Chicago: Chicago University Press, 1995.

29 Montgomery Hunter K. Doctors' stories: the narrative structure of medical knowledge. Princeton: Princeton University Press, 1992.

30 Macintyre A. After virtue: a study in moral theory. Notre Dame: University of Notre Dame Press, 1981.

31 Ricoeur P. Time and narrative [vol 3]. Chicago: University of Chicago Press, 1988.

32 Ricoeur P. Life in quest of narrative. In: Wood D, ed. On Paul Ricoeur, narrative, and interpretation. London: Routledge, 1991:20-33.

33 Ricoeur P. Oneself as another. Chicago: University of Chicago Press, 1992. 
34 Urban Walker M. Moral understandings London: Routledge, 1998.

35 Foucault M. What is an author? In: Faubion JD, ed. Essential works of Foucault [vol 2] 1954-1984. New York: The New Press 1994:222

36 Council on Ethical and Judicial Affairs. Surrogate decision making. Chicago: Council on Ethical and Judicial Affairs, AMA: 2001; no 119, June.
37 Kuczewski MG Commentary, narrative views of personal identity and substituted judgment in surrogate decision making. J Law Med Ethics substituted judgm

38 Montgomery Hunter K, Charon R, Coulehan JL. The study of literature in medical education. Acad Med 1995;70:787-95).

39 Hudson Jones A. The color of the wallpaper: training for narrative ethics. HEC Forum, 1999;11:58-66.

\section{Association for Medical Humanities - Second Annual Conference}

\section{MEDICINE AND THE HUMANITIES: TOWARDS INTERDISCIPLINARY \\ PRACTICE \\ UNIVERSITY OF WALES SWANSEA \\ 19-21 JULY 2004 \\ CALL FOR PAPERS}

Abstracts are invited for short, fifteen-minute papers on topics falling within any of the conference themes to be explored in the parallel sessions listed below:

- Arts and Health

- History

- Literature

- Medical Humanities in International Perspective

- Medical Humanities in the Medical Curriculum

- Medical Humanities in the Nursing Curriculum

- Music

- Philosophy

- Poetry and Music: Readings and Recitals

- Reflective Practice

- Religion

- Visual Media

Abstracts of between $\mathbf{2 0 0}$ and $\mathbf{3 0 0}$ words should be submitted by e-mail on a pro-form available from the Conference's Academic Administrator, Dr Alison Golby la.golby@ swan.ac.uk). They should identify the theme, give a title, and include name, affiliation, postal address, and telephone number. The deadline is 27 February 2004. Decisions will be communicated by 23 April 2004. Those wishing to receive further details of the Conference should send their contact details to Dr Golby.

Conference Organizers: Professor Anne Borsay, Dr Paul Wainwright, and Dr David Greaves, Centre for Philosophy, Humanities and Law in Healthcare, School of Health Science, University of Wales, Swansea. 